Check for updates

The BMJ

Cite this as: BMJ 2022;376:0261 http://dx.doi.org/10.1136/bmj.o261 Published: 08 February 2022

\section{Should I send my colleague a Valentine's Day card?}

\author{
While almost a fifth of people meet their significant other at work, Ingrid Torjesen finds out if it's \\ acceptable to send a Valentine's card to a colleague
}

Ingrid Torjesen

\section{It may be better to keep workplace interactions professional}

Catherine Wills, deputy head of advisory services, Medical Defence Union (MDU), says, "Many romances start in the workplace and a Valentine's card between colleagues could be the start of a successful relationship. In addition, friends sometimes share cards to cheer each other up or for a joke. It's important to be aware, however, that not everyone may take kindly to receiving a romantic card in the workplace. Even when sent anonymously, Valentine's wishes can upset, embarrass, or offend the recipient. They may even feel they're being harassed, particularly if a card is sent by someone in a senior position.

"In Good Medical Practice the General Medical Council says you must treat colleagues with respect and not unfairly discriminate against them by allowing personal views to affect professional relationships. In the MDU's experience, it's not unusual for GMC investigations to involve allegations that arise because colleagues have found each other's behaviour inappropriate. The person being complained about is often alarmed to learn that the person making the complaint has a very different perception of an action from the one they intended.

“Valentine’s cards from patients can also present doctors with a dilemma. You can minimise your chances of receiving romantic advances from patients by establishing firm professional boundaries. Similarly, it may be better to keep workplace interactions on a professional level to avoid blurred boundaries.”

\section{Think about where you want them to open it}

Liz O'Riordan, author and former breast cancer surgeon, says, "I was one of those girls who never got Valentine's cards at school. I got my first when I was a house officer. It had been left in my tray in the doctors' office-a bright red envelope for everyone to see. I remember blushing when my senior house officer picked it up and demanded I open it. I wanted the ground to swallow me whole. I recognised the handwriting: it was from one of the married registrars who used to tease me because I was single. I dropped it in the bin and went to start the ward round.

"Fast forward ten years later. After seeing countless relationships end in disaster, I had sworn that I would never mix work and romance. It was just too complicated to date someone I worked with. And then I got drunk and admitted to my best friend that I fancied my boss, but he was on the council of the
Royal College of Surgeons of England and I didn't want to be known as the registrar who slept her way to the top.

"It turned out that my boss felt the same. The day I moved to another hospital, he asked me out and we've just had our tenth wedding anniversary.

"I guess my answer to the question is a cautious 'yes.' Although secret Valentine's cards can be a lot of fun, they can also cause a lot of shame and misery. If the person is someone you care about, first think about where you want them to open it and whether it should be done in private."

\section{Your colleague may regard it as inappropriate}

Sheena Harris, human resources consultant at HR Solutions, says, "It's generally accepted that personal relationships within the workplace do occur and can bring about mutual benefits, including stronger commitment to the success of the employing organisation, cross functional collaborations, and reduced recruitment costs through recommendations.

"While there's no UK legislation governing relationships in the workplace, it's good practice for organisations to have a policy on personal relationships at work in order to ensure that, where such relationships exist, the behaviour of all parties remains appropriate and the relationship doesn't have any detrimental impacts. These could include conflicts of interest or inconsistent treatment with reporting lines, unfair approaches to recruitment and selection such as preferential treatment, and inappropriate behaviour in the workplace.

"Where two people already have a personal relationship outside of the workplace, sending a Valentine's Day card to a partner who is also a colleague may therefore be deemed appropriate. However, what if there is no pre-existing romantic relationship? In this context and taking into consideration Valentine's Day is ordinarily associated with romance, the colleague receiving the card may regard this as unwanted, unprofessional, and inappropriate behaviour. One serious consequence can be allegations of sexual harassment which could also be linked to sex discrimination under the Equality Act (2010). For this reason, we would not encourage the sending of Valentine's Day cards to colleagues.

"In addition to having a policy on personal relationships at work, it's also recommended that organisations have policies on bullying and harassment and equal opportunities in order to 
reinforce appropriate workplace behaviours and expectations.” 